\title{
Modelling of Ballistic Impact over a Ceramic-Metal Protection System
}

\author{
Leandro Neckel, ${ }^{1}$ Dachamir Hotza, ${ }^{2}$ Daniel Stainer, ${ }^{3}$ \\ Rolf Janssen, ${ }^{4}$ and Hazim Ali Al-Qureshi ${ }^{5}$ \\ ${ }^{1}$ Universidade do Extremo Sul Catarinense (UNESC), Unidade Acadêmica de Ciências, Engenharias e Tecnologia, \\ 88806-000 Criciúma, SC, Brazil \\ ${ }^{2}$ Universidade Federal de Santa Catarina (UFSC), Centro Tecnológico, Departamento de Engenharia Química, \\ 88040-900 Florianópolis, SC, Brazil \\ ${ }^{3}$ Construções Mecânicas Cocal Ltda, 88845-000 Cocal do Sul, SC, Brazil \\ ${ }^{4}$ Hamburg University of Technology (TUHH), Institute of Advanced Ceramics, 21073 Hamburg, Germany \\ ${ }^{5}$ Universidade Federal de Santa Catarina (UFSC), Centro de Engenharia da Mobilidade, 89218-000 Joinville, SC, Brazil
}

Correspondence should be addressed to Dachamir Hotza; dhotza@gmail.com

Received 24 February 2013; Revised 26 September 2013; Accepted 1 October 2013

Academic Editor: Augusto Deus

Copyright (c) 2013 Leandro Neckel et al. This is an open access article distributed under the Creative Commons Attribution License, which permits unrestricted use, distribution, and reproduction in any medium, provided the original work is properly cited.

\begin{abstract}
The behavior of ceramic-metal protection against a projectile impact is modeled. The model takes into account the mass and velocity for each stage of the phenomenon. A former model was modified considering more realistic parameters such as geometries and deformation profile. To analyze the model, simulations on different parameters have been run. The impact results of different ballistic projectiles were simulated, and the movement was plotted. In addition, a deterministic simulation on the mechanical properties of the back metal plate properties was done.
\end{abstract}

\section{Introduction}

Gonçalves et al. [1] have developed a mathematical approach to the behavior of a two-layer system protection of ceramicmetal system against high speed impact. The scheme of the protection is presented in Figure 1. The ceramic layer erodes the projectile, and the back metal plate is responsible for absorbing the remaining energy by plastic deformation. The mathematical model separates the penetration into three different stages and proposes a deterministic equation that explains the deflection of the metal plate. The movement equations were manipulated to find a single problem for velocity and mass separately for each stage. The data and initial parameters provided by the original work [1] were used for the differential equations found. The metal deformity was reevaluated by deducing the deterministic equation. A more realistic shape parameter was considered for the postimpact curvature, and the volume approach was improved. Finally, the solution was plotted and compared to former results [1].
The model was better understood once the solutions were used to simulate different impacts over the system. Initially, properties of some ballistic projectiles were used to prevent the shock absorption. In addition, the mechanical properties of the metallic plate were modified intending to observe the effect on the final deformation.

A previous work [2] has focused on the study of the movement evolution of the projectile. This work has continued to analyze the penetration of the projectile searching for the understanding of the final deformation.

The set of data generated in the simulations together with the newly developed equations for impact and shock absorption were, in conclusion, observed as an advance for the understanding of high speed impact phenomena.

\section{Materials and Methods}

The software Maplesoft Maple V12 was used to solve the system. Gonçalves et al. work [1] provided all materials, 


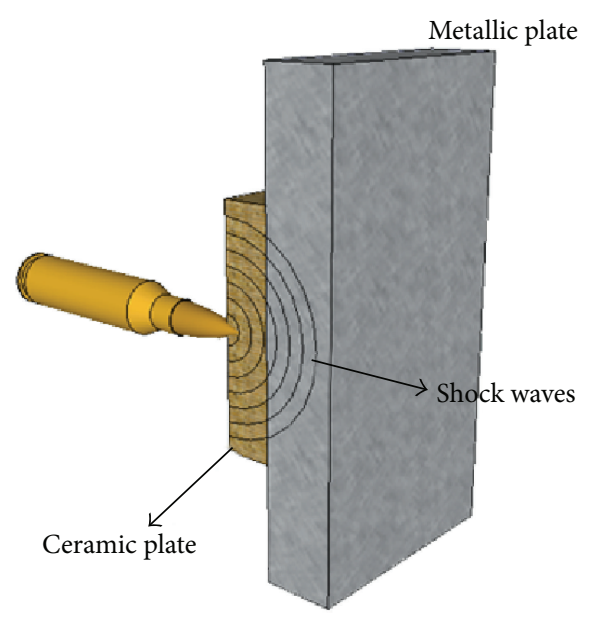

Figure 1: Proposal of a two-layer protection made by Gonçalves et al. [1].

constant values, and initial parameters necessary. Moreover, the projectile specifications used were from rifle bullets.

The mathematical model of the penetration process is divided into three stages. The first represents the initial impact and erosion of the head of the projectile. In this situation there is no penetration into the protection. The force against the projectile is

$$
m(t) \frac{d}{d t} v(t)=-Y A_{p}
$$

and the variation in the geometry is given by

$$
\frac{d}{d t} m(t)=-A_{p} \rho_{p} v(t)
$$

where $Y$ is the dynamic yielding of the projectile and $A_{p}$ is the effective contact area of the projectile. Also, $\rho_{p}$ is the density of the projectile's material. According to Tabor [3], the dynamic hardness of a metal is the pressure with which it resists local indentation by a rapidly moving indenter. The first approximation for the $Y$ value is a constant and not necessarily the same as the static pressure necessary to cause plastic flow. The actual value of the dynamic yield pressure strongly depends on the velocity of the impact and the projectile geometry. Tabor [3] also cites different methods to estimate this value. For simplification, following the original work [1], this value will be considered a fraction of the static hardness of the projectile material.

The impact generates a shock wave that travels through the material and reflects back cracking the ceramic plate. This shock wave is extremely fast and runs through the protection in a small fraction of a second. Theoretically, the sum of the incoming with the returning wave generates a region of high stress. This region is easily observed as a cone in the solids, which fits with the cracking region. Figure 2 demonstrates a single scheme for the initial impact and the propagating shock waves.

The shape and size of the ceramic tile can also affect the protection performance. The crack cone formation allows the

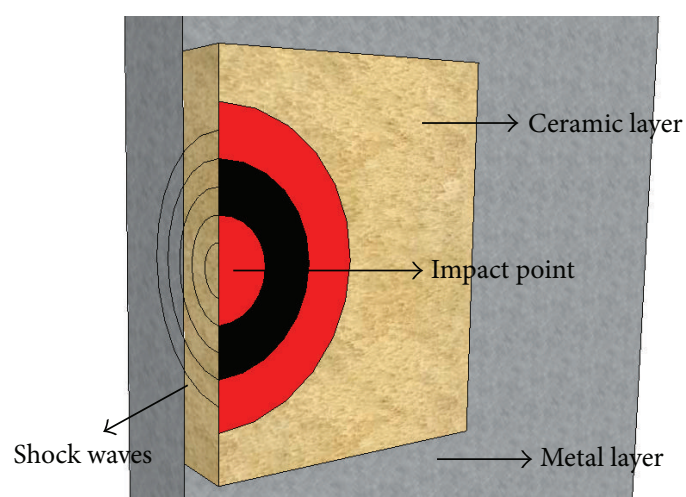

FIgURE 2: First stage of the impact. The collision generates a shock wave that travels through the armor.

necessary scattering to provide enough ceramic particles for the projectile erosion. With smaller geometry, the crack cone would not be properly formed once the constructive interference of the shock waves would not only occur longitudinally but also transversally. Those considerations were not taken into account in this model.

In the second stage the penetration starts pushing an interface projectile-ceramic with velocity $u(t)$. This interface is a small portion of ceramic in contact with the projectile which moves together but with different initial velocity. Thus, the force against the projectile is the same, but the difference of the velocities $v(t)$ and $u(t)$ gives the erosion ratio:

$$
\frac{d}{d t} m(t)=-A_{p} \rho_{p}(v(t)-u(t))
$$

It is important to note that the erosion ceases when $u(t)$ is equal to $v(t)$. In this moment, the interface reaches the same velocity as the projectile. With this, if there is no difference between both velocities, there is no stress applied in the projectile or interface material.

The modified hydrodynamic theory given by Tate [4] introduced the dynamic yielding $(Y)$ and the resistance against penetration $(R)$ adopted for the ceramic in this case. Tate's law is given by

$$
Y+\frac{1}{2} \rho_{p}(v(t)-u(t))^{2}=R+\frac{1}{2} \rho_{c} u(t)^{2},
$$

where $\rho_{c}$ is the density of the ceramic material. Tate's equation is used as an important auxiliary equation to solve the model. This will be present in the next section of this work.

The second stage ends when $v(t)=u(t)$. After this, the final fraction of the movement is given by

$$
m_{p r} \frac{d}{d t} v(t)=-R A_{p}
$$

where $m_{p r}$ is the remaining mass of the projectile. The metal plate absorbs the final kinetic energy by plastic deformation. Simultaneously to the penetration of the projectile, the metallic base will move and will be deformed elastically. However, the energy produced by this elastic energy will 
be low and will be neglected [1]. Once the first and second stage end, the main part of the projectile kinetic energy is absorbed by ceramic scattering and projectile erosion and can be computed using $m_{p r}$ and the velocity obtained in the beginning of the third stage. Due to the deceleration of the bullet caused by the ceramic layer, the metallic plate may not be perforated. In this case, the secondary layer will suffer plastic deformation, and the plastic energy consumed by the plate can be expressed in terms of effective stress and strain as

$$
E_{p}=\int_{v}\left(\int_{0}^{\bar{\varepsilon}} \bar{\sigma} \partial \bar{\varepsilon}\right) d V
$$
law

It is considered a stress-strain curve given by the power

$$
\bar{\sigma}=A \cdot(\bar{\varepsilon})^{n}
$$

and the deflection profile of the plate given by

$$
w(r)=w_{0} e^{(-k r / D)},
$$

where $w_{0}$ is the maximum deflection of the dimple shape, $D(\mathrm{~m})$ is the radius of the projectile, $k$ (dimensionless) is a deflection profile constant that can be determined experimentally, and $r(\mathrm{~m})$ is the radial distance of the impacting projectile center.

Assuming that the material will be bulged in an axis symmetric mode, the effective strain can be written in terms of the radial strain as

$$
\bar{\varepsilon}=2 \varepsilon_{r}
$$

For a small displacement, the radial strain can be approximated to $[1,5,6]$

$$
\varepsilon_{r}=\frac{1}{2}\left(\frac{\partial}{\partial r} w(r)\right)^{2}
$$

Considering a geometry of a small dimple given by $2 \pi r h \delta r$, where $h$ is the thickness of the plate $[7,8]$, the manipulation of the equations gives

$$
E_{p}=\frac{2 \pi h A}{n+1}\left(-\frac{k w_{0}}{D}\right)^{2(n+1)} \int_{0}^{\infty} e^{[(-k r(2 n+2)) / D]} r \partial r .
$$

Considering the physical nature of most constants, it is possible to suppress the negative sign generated by the derivation demonstrated in (11). Also, the radial variation of the deflection profile is mirrored in the $x$-axis, which demonstrates that this ratio can be used as its own module. Now it gives

$$
E_{p}=\frac{2 \pi h A}{n+1}\left(\frac{k w_{0}}{D}\right)^{2(n+1)} \int_{0}^{\infty} e^{[(-k r(2 n+2)) / D]} r \partial r .
$$

The solution for the expression is given by

$$
E_{p}=\frac{1}{2} \frac{\pi h A(k / D)^{2 n} w_{0}^{2(n+1)}}{(n+1)^{3}} .
$$

After the initial impact, the movement of the interface starts deforming the metallic plate. It can be argued that, initially, the metal layer is compressed due to high pressure generated by the impact. In addition, the plate does not move significantly because of the low interface velocity. In this way, it is possible to affirm that the deflection of stainless steel plate starts at the end of the second stage of penetration.

Considering that the plastic energy absorbed by the metal plate is equal to the kinetic energy of the projectile in the end of the second stage, it is possible to write the final deflection of the plate as

$$
w_{0}=\left(\frac{m_{p r} v_{p}^{2}(n+1)^{3}}{\pi h A(k / D)^{2 n}}\right)^{1 /(2 n+2)}
$$

where $v_{p}$ is the velocity of the projectile at the end of the second stage.

\section{Results and Discussion}

The movement solutions were obtained divided by the stages and by mass and velocity. The equations needed to be manipulated together to find a unique solvable problem for mass and velocity for each stage. First it was necessary to find a differential equation with a unique function. For the first stage it was

$$
\frac{d^{2}}{d t^{2}} v(t)=-\frac{\rho_{p} v(t)((d / d t) v(t))^{2}}{Y}
$$

for the velocity and

$$
\frac{d^{2}}{d t^{2}} m(t)=\frac{Y A_{p}^{2} \rho_{p}}{m(t)}
$$

for the mass. The auxiliary Tate's equation was used in the manipulation to formulate a second degree equation with the function $u(t)$ as a result. Naturally, one of the results was not considered due to its particularity for being a complex solution, which does not have a physical interpretation. The $u(t)$ written as a function of $v(t)$ could be used to formulate the second stage equations. These sentences are given by

$$
\begin{aligned}
& \frac{d^{2}}{d t^{2}} v(t) \\
& =\left(\rho_{p}\left(\frac{d}{d t} v(t)\right)^{2}\right. \\
& \quad \times\left(v(t)\left(2 \rho_{p}-\rho_{c}\right)\right. \\
& \left.\left.\quad+\sqrt{2 \rho_{p} R-2 \rho_{p} Y+2 \rho_{c} Y-2 \rho_{c} R+\rho_{c} \rho_{p} v(t)^{2}}\right)\right) \\
& \quad \times\left(Y\left(\rho_{c}-\rho_{p}\right)\right)^{-1}
\end{aligned}
$$


for the velocity and

$$
\begin{aligned}
& \frac{d^{2}}{d t^{2}} m(t) \\
& =-\left(Y A^{2} \rho_{c} \rho_{p}\right. \\
& \left.\quad \times\left(m(t)\left(-\rho_{c}+\frac{((d / d t) m(t)) \rho_{c} \rho_{p}}{\sqrt{((d / d t) m(t))^{2} \rho_{c} \rho_{p}-2 \rho_{c} \rho_{p}^{2} A_{p}^{2} R+2 \rho_{c} \rho_{p}^{2} A_{p}^{2} Y}}\right)\right)^{-1}\right)
\end{aligned}
$$

for the mass. For the deflection of the metal plate, the new deflection profile was adopted considering the null derivative in $r=0$ :

$$
w(r)=w_{0} e^{\left(-k_{\bmod } r^{2} / D\right)},
$$

where $w_{0}$ is the maximum deflection of the dimple shape, $D(\mathrm{~m})$ is the radius of the projectile, $k_{\text {mod }}\left(\mathrm{m}^{-1}\right)$ is a modified deflection profile constant, which is determined experimentally, and $r(\mathrm{~m})$ is the radial distance of the impacting projectile center.

Also, the dimple shape after the impact, shown by Figure 3, was then approximated to the volume of a small paraboloid given by

$$
d V=\frac{4}{3} \pi r h \partial r
$$

The newly deduced metal final deformity equation is now given by

$$
\begin{aligned}
w_{0}=\left(D \left(\frac{1}{2}\left(m_{p r} v_{p r}^{2}(n+1)\right)\right.\right. \\
\quad \times\left(A \pi h \cdot \Gamma\left(n+\frac{5}{2}\right)\right. \\
\left.\left.\left.\quad \cdot\left(\frac{2 k_{\bmod }(n+1)}{D}\right)^{-n-(5 / 2)}\right)^{-1}\right)^{1 /(2 n+2)}\right) \\
\times\left(2 k_{\text {mod }}\right)^{-1},
\end{aligned}
$$

where $k_{\bmod }$ is the modified profile constant and $\Gamma$ is the mathematical gamma function, which is an extension of the factorial function, with its argument shifted down by 1 , to real and complex numbers.

In addition, for a solid two-layered system, it is necessary to consider the time needed for the generated wave to reflect in the back part of the protection and return to the initial point and, furthermore, start to crack the ceramic layer. The time needed for the wave to travel and reflect back is given by

$$
t_{i}=\frac{2 e_{c}}{c_{c}}+\frac{2 e_{m}}{c_{m}},
$$

where $e_{c}$ and $c_{c}$ are, respectively, the thickness and the longitudinal velocity of sound for the ceramic material and $e_{m}$ and $c_{m}$ are the same constants for the metallic material. It is known that the shock wave travels with the longitudinal
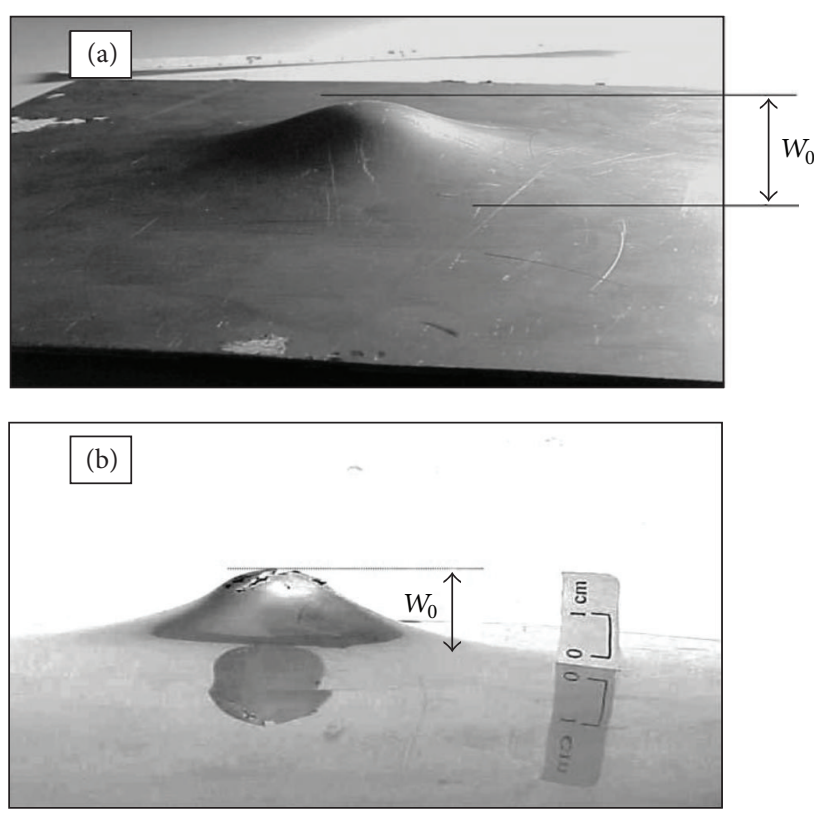

FIGURE 3: Shape of the metallic plate after impact.

TABle 1: Properties of the steel nucleus of the projectile.

\begin{tabular}{lc}
\hline Property & Value \\
\hline Initial velocity $(\mathrm{m} / \mathrm{s})$ & 835 \\
Mass $(\mathrm{g})$ & 9.54 \\
Vicker's hardness $(\mathrm{HV})$ & 817.5 \\
Dynamic yield stress $(\mathrm{GPa})$ & 2.82 \\
Density $\left(\mathrm{g} / \mathrm{cm}^{3}\right)$ & 8.41 \\
Diameter $(\mathrm{mm})$ & 7.62 \\
\hline
\end{tabular}

velocity of sound in the solid, and this velocity can be calculated by [9]

$$
c=\sqrt{\frac{E}{\rho}},
$$

where $E$ is the elastic modulus of the material.

The substitution of (22) in (21) gives

$$
t_{i}=2 e_{c} \sqrt{\frac{\rho_{c}}{E_{c}}}+2 e_{m} \sqrt{\frac{\rho_{m}}{E_{m}}},
$$

where $E_{c}$ and $E_{m}$ are the elastic modulus for the ceramic and metallic material, respectively.

The first results were obtained using the projectile and system data presented in the former work [1]. Table 1 presents the projectile data. In the former work, basically two different compositions were used for the ceramic plate during the experimental tests. The composition and reference properties of the ceramic plates are shown in Tables 2 and 3, respectively.

In Figures 4(a) and 4(b), the upper curve, $v(t)$, corresponds to the projectile velocity and the lower curve, $u(t)$, 
TABLE 2: Ceramic compositions.

\begin{tabular}{lccc}
\hline Composition & $\begin{array}{c}\mathrm{Al}_{2} \mathrm{O}_{3} \mathrm{~A}-1000 \mathrm{SG} \\
\text { (wt.\%) }\end{array}$ & $\begin{array}{c}\mathrm{Al}_{2} \mathrm{O}_{3} \text { Tubular } \mathrm{T}-60 \\
\text { (wt.\%) }\end{array}$ & $\begin{array}{c}\mathrm{TiO}_{2} \\
\text { (wt.\%) }\end{array}$ \\
\hline $\mathrm{B}$ & 90 & 8 & 2 \\
$\mathrm{C}$ & 85 & 13 & 2 \\
\hline
\end{tabular}

TABLE 3: Mechanical and physical properties of the ceramic plates.

\begin{tabular}{lcc}
\hline \multirow{2}{*}{ Property } & \multicolumn{2}{c}{ Composition } \\
& B & $\mathrm{C}$ \\
\hline Weibull modulus $(\mathrm{m})$ & 8.4 & 8.8 \\
Mean strength parameter, $\sigma_{50}(\mathrm{MPa})$ & 175.0 & 171.3 \\
Reference rupture strength, $\sigma_{0}(\mathrm{MPa})$ & 182.8 & 178.5 \\
Vicker's hardness $(\mathrm{HV})$ & 1551.4 & 1259.8 \\
Resistance against penetration on & 4.43 & 3.60 \\
ceramic, $R_{c}(\mathrm{GPa})$ & 3.90 & 3.80 \\
Density $\left(\mathrm{g} / \mathrm{cm}^{3}\right)$ & $18 \pm 8$ & $22 \pm 9$ \\
Average grain size $(\mu \mathrm{m})$ &
\end{tabular}

TABLE 4: Fraction of loss of velocity, mass and energy of the projectile in the three stages (adapted from previous work [2]).

\begin{tabular}{lccc}
\hline Stage & Velocity loss (\%) & Erosion (\%) & Absorbed energy (\%) \\
\hline 1st & 10.62 & 19.18 & 35.73 \\
2nd & 30.27 & 40.77 & 50.32 \\
3rd & 59.10 & - & 13.93 \\
\hline
\end{tabular}

shows the equivalent results obtained in a previous work $[1,2]$. Figure 4(a) presents the results obtained in this work, and Figure 4(b) shows the former work [1] results.

In both graphs it is possible to observe the different stages of penetration in the graph. During the first stage, there is no interface velocity. In the beginning of the second stage, the interface begins to move tending to reach the same velocity as the projectile. The third and final stage begins with the projectile and interface velocities equalized. During this final fraction of the movement, both projectile and interface decelerate together. With the solutions it is possible to estimate the fraction of mass, velocity, and energy lost in each stage. These values are presented in Table 4 .

There were more two ceramic compositions presented in the material selection. However, both of these structures were not stable enough to be molded in the system.

The values of the constants were given by the former work [1] together with the initial velocities and mass. The different ceramic plate thicknesses tested by the authors of the former work are also declared in the table. In addition, the first stage duration, calculated using (24), is also presented due to the different thickness and composition. Most of the constants and mechanical properties $[10,11]$ used in the model are presented in Table 5.

These data (21) together with the solved movement equations can give the results for the maximum deflection

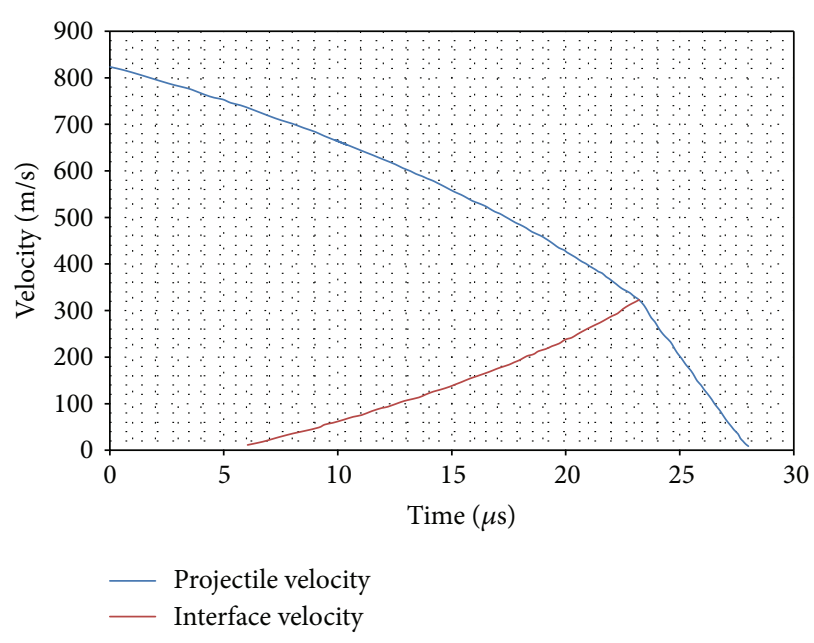

(a)

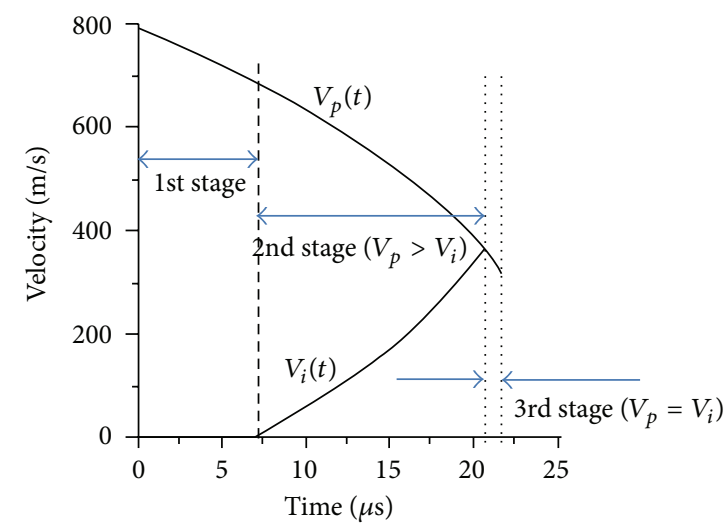

(b)

FIGURE 4: Velocity against time for (a) this work and (b) previous work $[1,2]$, respectively.

of the back metal plate. The comparisons are presented in Table 6. It is possible to note that the proportional errors both in the original and in the modified theory (OT and MT) are of the same magnitude. This fact is related to the simplicity of the model and the amount of neglected variable in the energy absorption, such as impact angle, ceramic porosity, and metal grain size, among others.

However, the results of the maximum deflection showed that the new theories can generate good results not only for the high speed impacts, but also for lower velocities, differently from the former theory. Simulations for different calibers [12] were performed using the new developed theory. The tested calibers with their specification are shown in Table 7. The movement evolutions for the different calibers are presented in Figure 5. Finally, the results are presented in Table 8 . In addition, Table 8 also presents the penetration into the ceramic layer by each simulated caliber. This can be calculated by numeric integration of second stage movement equations, considering that the main penetration occurs in this stage. 
TABLE 5: Values of the constants used in the modified model.

\begin{tabular}{|c|c|c|c|c|}
\hline Symbol & Property & & Value & \\
\hline$\rho_{c}$ & Ceramic density $\left(\mathrm{g} / \mathrm{cm}^{3}\right)$ & $\begin{array}{c}\text { Composition B } \\
3.9\end{array}$ & & $\begin{array}{c}\text { Composition C } \\
3.8\end{array}$ \\
\hline$E_{c}$ & Ceramic elastic modulus (GPa) & & 300 & \\
\hline$e_{c}$ & Ceramic thickness (mm) & 11.3 & 9.3 & 7.3 \\
\hline$R_{c}$ & Resistance against penetration on ceramic (GPa) & $\begin{array}{c}\text { Composition B } \\
4.43\end{array}$ & & $\begin{array}{c}\text { Composition C } \\
3.60\end{array}$ \\
\hline$\rho_{m}$ & Metal density $\left(\mathrm{g} / \mathrm{cm}^{3}\right)$ & & 7.77 & \\
\hline$E_{m}$ & Metal elastic modulus (GPa) & & 193 & \\
\hline$e_{m}$ and $h$ & Metal thickness (mm) & & 15 & \\
\hline$A$ & Metal strength (MPa) & & 935 & \\
\hline$n$ & Metal hardening exponent & & 0.29 & \\
\hline$k_{\text {mod }}$ & Metal modified deflection profile constant $\left(\mathrm{m}^{-1}\right)$ & & 0.0018 & \\
\hline Y & Projectile dynamic yielding (GPa) & & 2.82 & \\
\hline$\rho_{p}$ & Projectile density $\left(\mathrm{g} / \mathrm{cm}^{3}\right)$ & & 8.41 & \\
\hline
\end{tabular}

TABLE 6: Comparison of the former and new results.

\begin{tabular}{|c|c|c|c|c|c|c|c|c|}
\hline \multirow{2}{*}{ Composition } & \multirow{2}{*}{$\begin{array}{l}\text { Thickness } \\
(\mathrm{mm})\end{array}$} & \multirow{2}{*}{$\begin{array}{l}\text { Duration of the } \\
\text { 1st stage }(\mu \mathrm{s})\end{array}$} & \multirow{2}{*}{ Impact velocity $(\mathrm{m} / \mathrm{s})$} & \multicolumn{3}{|c|}{ Maximum deflection } & \multicolumn{2}{|c|}{ Errors } \\
\hline & & & & $\begin{array}{c}\text { Experimental } \\
\text { data }(\mathrm{mm})\end{array}$ & $\begin{array}{l}\text { Original } \\
\text { theory, OT } \\
(\mathrm{mm})\end{array}$ & $\begin{array}{l}\text { Modified } \\
\text { theory, MT } \\
\quad(\mathrm{mm})\end{array}$ & |OT| (\%) & $|\mathrm{MT}|(\%)$ \\
\hline $\mathrm{B}$ & 11.3 & 8.6 & 792.7 & 16.5 & 17.0 & 17.2 & 2.9 & 4.3 \\
\hline C & 11.3 & 8.7 & 858.2 & 20.0 & 17.6 & 18.4 & 13.6 & 8.8 \\
\hline B & 9.3 & 8.2 & 628.9 & 18.0 & 17.8 & 18.8 & 1.1 & 4.2 \\
\hline $\mathrm{C}$ & 9.3 & 8.2 & 651.1 & 17.5 & 17.7 & 18.3 & 1.1 & 4.3 \\
\hline B & 7.3 & 7.7 & 428.8 & 15.5 & 17.3 & 14.6 & 10.4 & 6.0 \\
\hline $\mathrm{C}$ & 7.3 & 7.8 & 448.4 & 13.0 & 16.6 & 13.0 & 21.7 & 0 \\
\hline
\end{tabular}

In Figure 5 it is possible to observe the marked region. This region in the graph corresponds to the probable area of velocity and time where the erosion does not occur. In addition, the shifts in the curvatures of the velocities represent the beginning of the third stage. This helps to investigate the effect of the ceramic's characteristics in the impact absorption and in the erosion. This graph and this model of simulation can be used to search for specific properties in the ceramic plate and/or to improve its shock absorption property.

The not highlighted region in Figure 5 represents a penetration stage where projectile erosion and ceramic scattering occur. If it is desired not to have a large deformation in the metallic plate, it is necessary to improve ceramic impact absorption. These improvements will affect $R_{c}, e_{c}$, and $E_{c}$, which will also modify the graph.

Considering the back metal plate as another important energy absorber and integrity maintainer for the system, a deterministic simulation was run using the new deformation law together with the deflection profile function. Then it gives

$$
\begin{aligned}
w(r)= & d\left(\left(\frac{1}{2}\right) m_{p r} v_{p r}^{2}(n+1)\right. \\
& \times\left(A \pi h \cdot \Gamma\left(n+\frac{5}{2}\right)\right. \\
& \left.\left.\left.\times\left(\frac{2 k_{\bmod }(n+1)}{d}\right)^{-n-(5 / 2)}\right)^{-1}\right)^{1 /(2 n+2)}\right) \\
& \cdot e^{\left(-\left(k_{\bmod } r^{2}\right) / d\right)} .
\end{aligned}
$$

The variable $r$ is the radial distance of the projectile impact. The maximum deflection as a function of the hardening exponent $n$ and the radial distance $r$ is presented in Figure 6. In addition, the effect of the thickness $h$ of the 
TABLE 7: Specifications of the different calibers used in the simulation.

\begin{tabular}{lcccc}
\hline Type & Specification & Bullet diameter $(\mathrm{mm})$ & Mass $(\mathrm{g})$ & Initial velocity $(\mathrm{m} / \mathrm{s})$ \\
\hline II & .357 Magnum & 9.07 & 10.2 & 453 \\
IIA & $9 \mathrm{~mm}$ & 9 & 8 & 373 \\
IIA & $.40 \mathrm{~S} \& \mathrm{~W}$ & 10.2 & 12 & 300 \\
IIIA & $.357 \mathrm{SIG}$ & 9.07 & 16 & 440 \\
IIIA & .44 Magnum & 11.2 & 16 & 460 \\
\hline
\end{tabular}

TABLE 8: Results of the simulation for several different calibers.

\begin{tabular}{lccccc}
\hline Type & Specification & Third stage velocity $(\mathrm{m} / \mathrm{s})$ & Third stage mass $(\mathrm{g})$ & Final deflection value $(\mathrm{mm})$ & Penetration in the ceramic $(\%)$ \\
\hline II & .357 Magnum & 170 & 6.66 & 19.48 & 87.5 \\
IIA & $9 \mathrm{~mm}$ & 129 & 5.80 & 18.71 & 41.4 \\
IIA & $.40 \mathrm{~S} \& W$ & 104 & 9.45 & 18.63 & 49.6 \\
IIIA & $.357 \mathrm{SIG}$ & 163 & 5.36 & 17.40 & 84.4 \\
IIIA & .44 Magnum & 197 & 10.38 & 20.15 & 90.1 \\
\hline
\end{tabular}

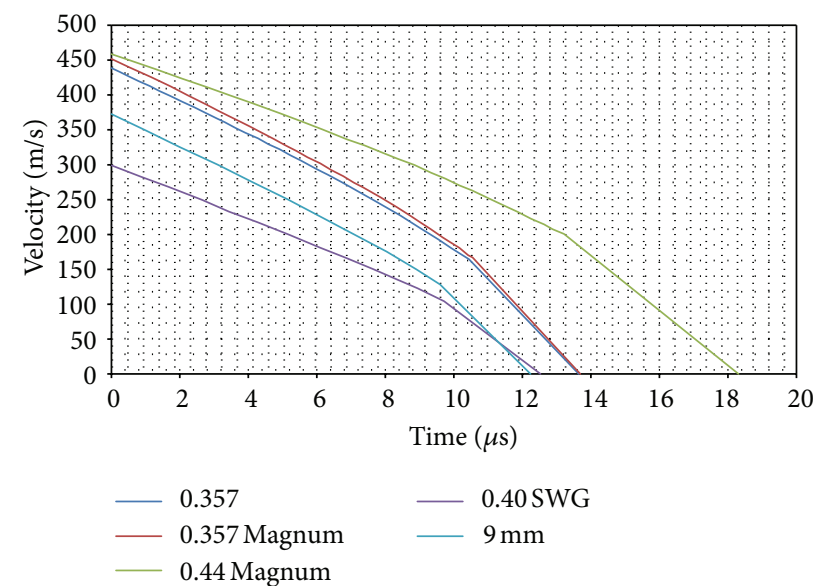

FIGURE 5: Movement evolution for the simulation on different calibers.

plate together with the radial distance of the impact center is presented in Figure 7.

Based on Figures 6 and 7, it is possible to affirm that the mechanical property $n$ and the thickness $h$ of the metal layer have an important effect on the maximum deflection. The $n$ constant demonstrates the ductile behavior of the material. However, if a lower deflection is required, it is important to note that a harder material could shear more easily depending on the energy of the projectile. Moreover, a change in the thickness of the metal plate will certainly affect the structure weight, which could be an aggravating factor in the carrier's mobility.

\section{Conclusions}

The values obtained from the model demonstrate how important the ceramic plate is in the protection, responsible for absorbing approximately $85 \%$ of the total energy. Moreover, the value for the deflection of the metal plate was close to

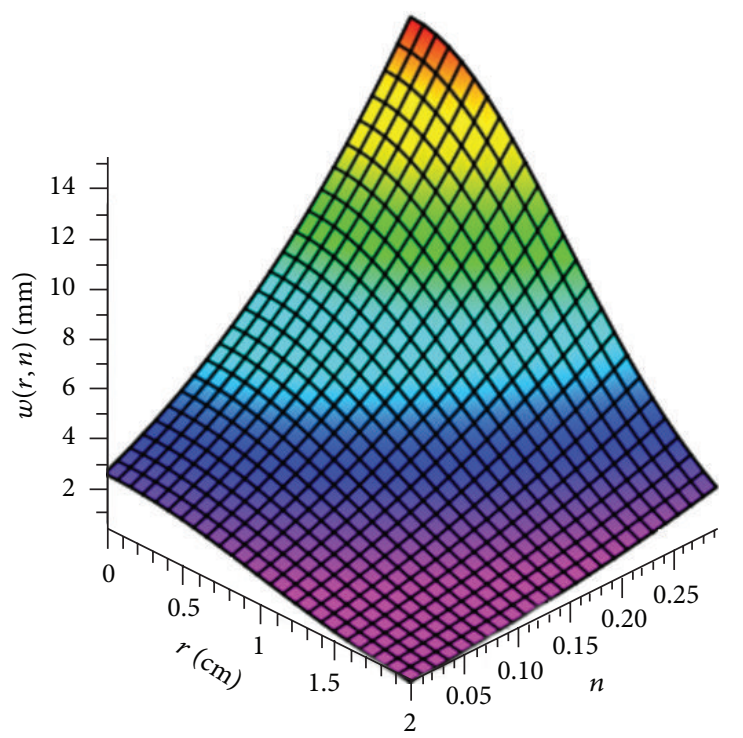

FIGURE 6: Deformation $w$ in function of the radial distance $r$ and the hardening exponent $n$.

the experimental data, which validates the model. Together with the optimized deflection equation the model could also prevent the effects of different projectile impacts.

In addition, the simulation demonstrated different aspects of the model and some predictable effects in collision phenomena. The control of the properties and its effects were analyzed with the developed computational method. Some of the effects predicted by the program could not be studied experimentally. However, future studies can use the presented results to validate the theory and, then, analyze some internal phenomena in a deeper way.

The present work is a theoretical analysis of the impact phenomenon in a specified type of protection. In the future studies, the current model and its solutions and simulations can be used to perform experimental test to evaluate the 


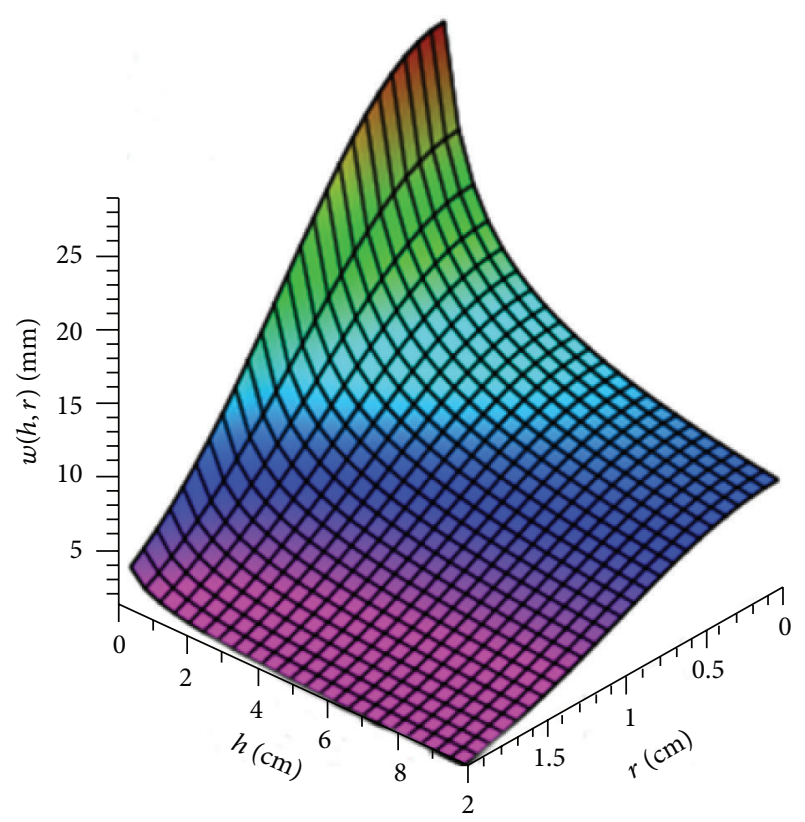

FIGURE 7: Deflection of the metallic plate $w$ in function of the metal thickness $h$ and radial distance $r$.

reliability of the model. Also, if the model can be considered valid for the impact, the considerations and formulations can be kept or improved to a more advanced modeling as finite element modeling (FEM). In addition, the experimental confirmation of the presented modeling also permits deeper investigation of the impact phenomenon, such as the effect of the interfacial friction between the projectile and sheared surfaces.

\section{Acknowledgments}

The authors wish to thank CAPES and CNPq for supporting this work.

\section{References}

[1] D. P. Gonçalves, F. C. L. de Melo, A. N. Klein, and H. A. Al-Qureshi, "Analysis and investigation of ballistic impact on ceramic/metal composite armour," International Journal of Machine Tools and Manufacture, vol. 44, no. 2-3, pp. 307-316, 2004.

[2] L. Neckel, D. Hotza, D. Stainer et al., "Solutions for impact over aerospace protection," Key Engineering Materials, vol. 488-489, pp. 25-28, 2012.

[3] D. Tabor, The Hardness of Metals, Oxford University Press, 1951.

[4] A. Tate, "A theory for the deceleration of long rods after impact," Journal of the Mechanics and Physics of Solids, vol. 15, no. 6, pp. 387-399, 1967.

[5] R. Hill, The Mathematical Theory of Plasticity, Oxford University Press, 1950.

[6] H. A. Al-Qureshi and J. D. Bressan, "Investigation of the degree of biaxiality on the limit strains in sheet metal stretching," in
Proceedings of the 9th North American Manufacturing Research Conference (NAMRC '81), pp. 538-541, 1981.

[7] D. Ishikura and H. A. Al-Qureshi, "An investigation of perforation of metallic and composite plates by projectiles," in Proceedings of the 5th Pan-American Congress of Applied Mechanics (PACAM '97), pp. 194-197, 1997.

[8] M. L. Wilkins, "Mechanics of penetration and perforation," International Journal of Engineering Science, vol. 16, no. 11, pp. 793-807, 1978.

[9] D. Halliday, R. Resnick, and J. Walker, Fundamentals of Physics, vol. 2, John Wiley \& Sons, New York, NY, USA, 4th edition, 1996.

[10] Accuratus, "Aluminum oxide, ceramic properties," http:// accuratus.com/alumox.html.

[11] Azom Materials, "Stainless steel, grade 304," http://www.azom .com/article.aspx? ArticleID $=965$.

[12] U.S. National Institute of Justice, "Ballistic resistance of body armor," NIJ Standard-0101.06, 2008. 

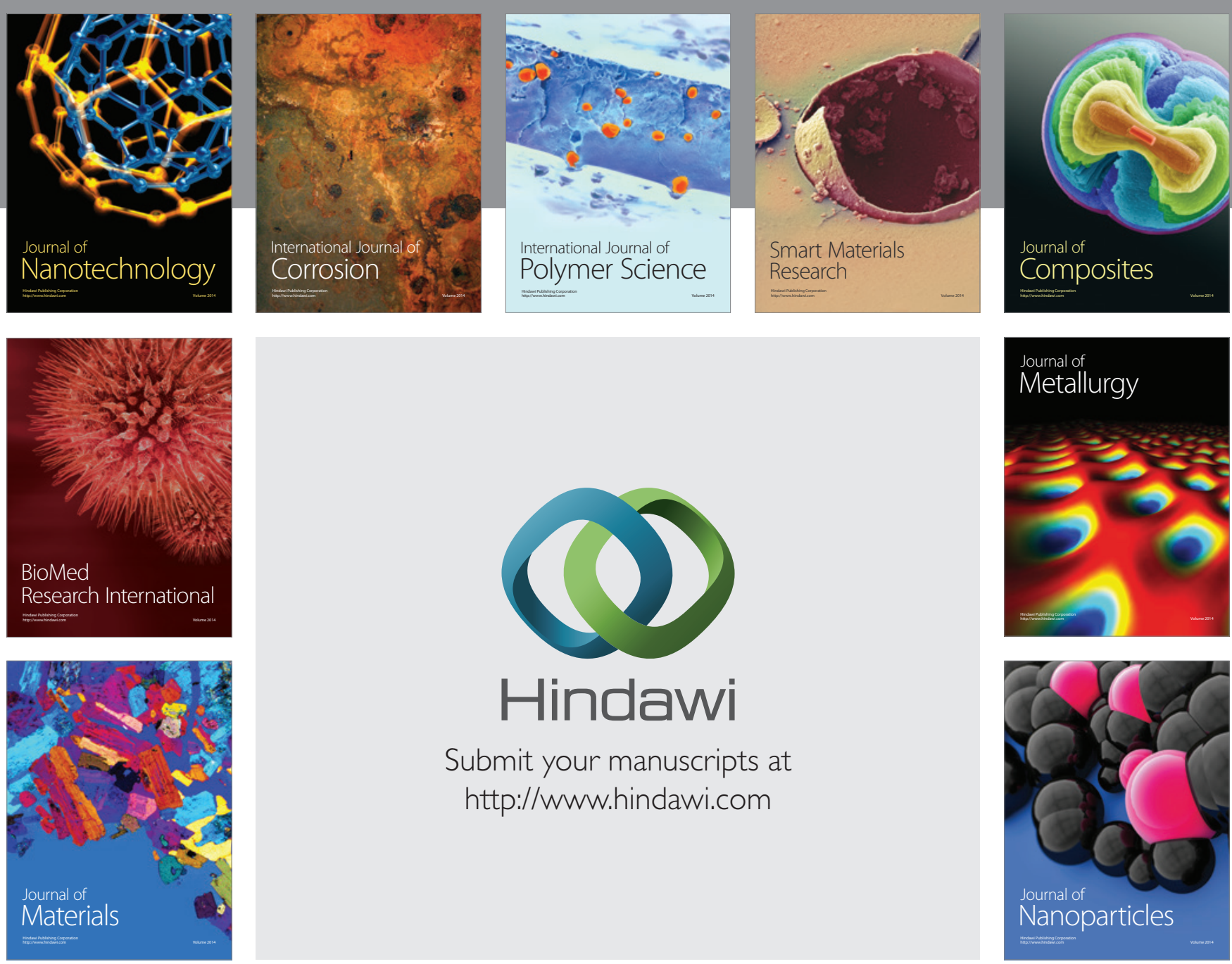

Submit your manuscripts at http://www.hindawi.com
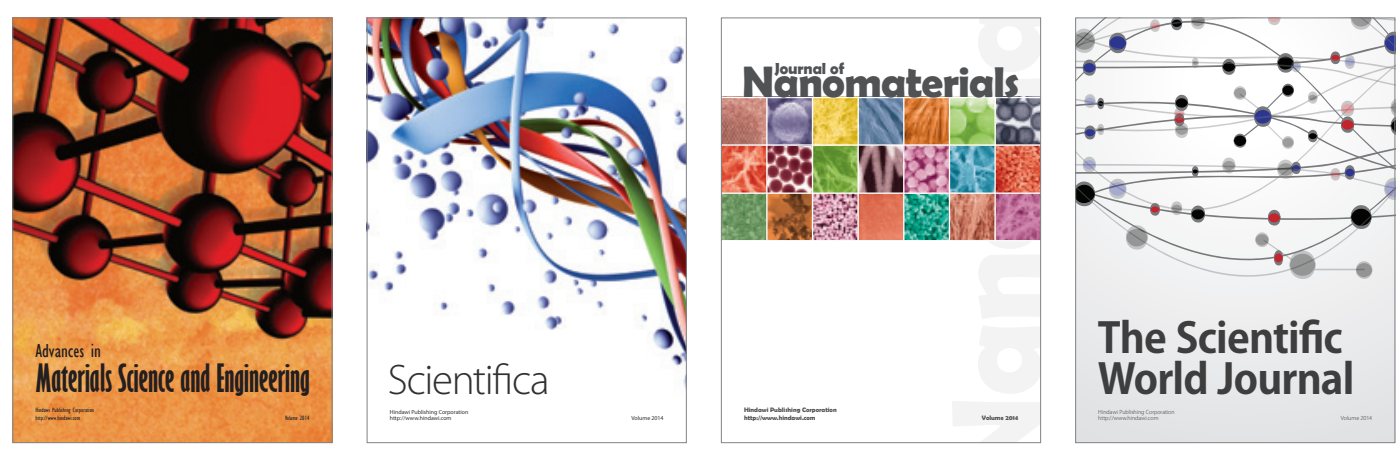

\section{The Scientific World Journal}
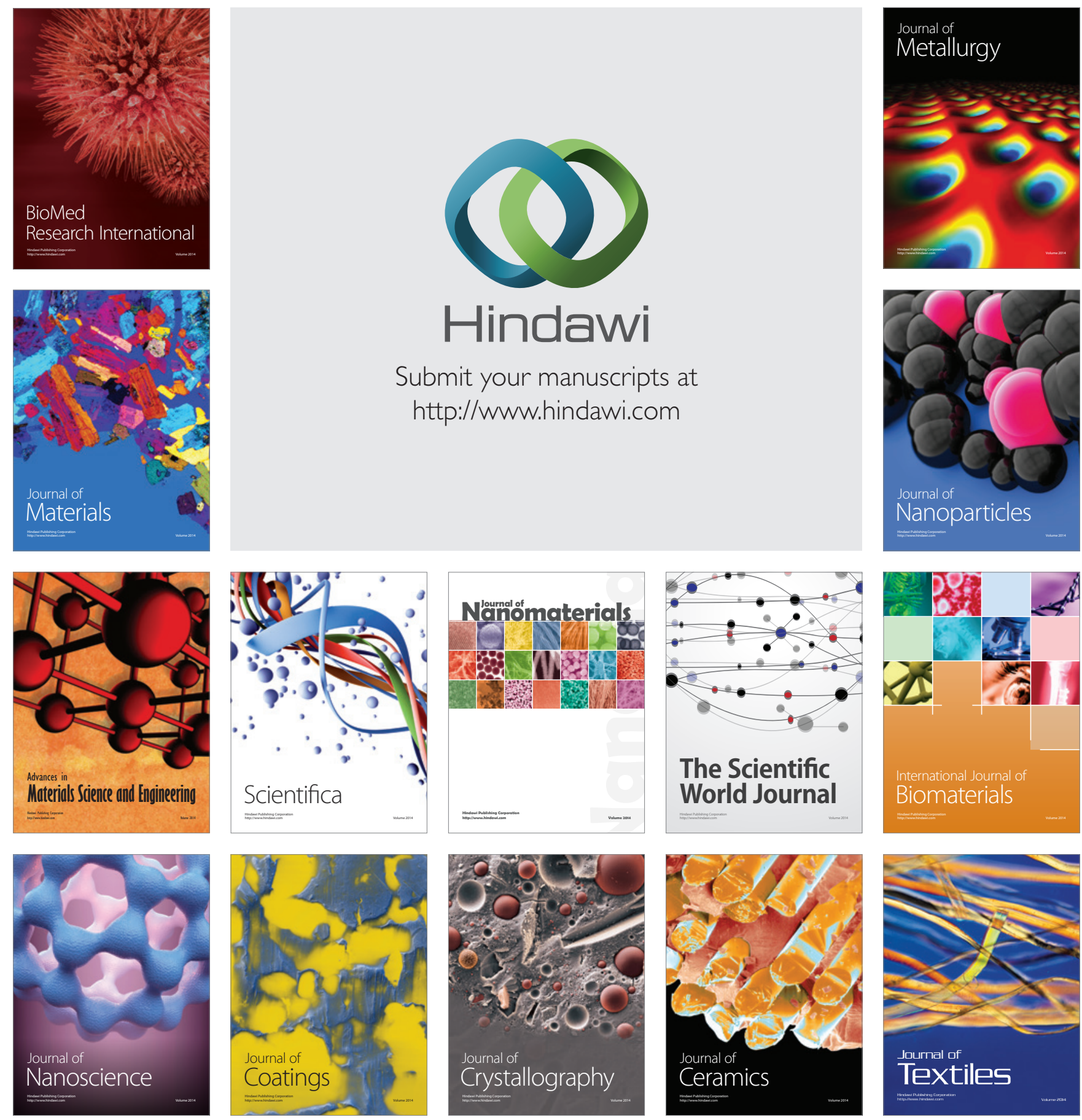